\title{
A concepção da metafísica ingênua de imagem: a crítica de Sartre a Descartes
} The conception of naive metaphysics of image: Sartre's critic of Descartes

\author{
HELTON LUCAS ROMUALDO'
}

Resumo: O que é uma imagem, fruto de uma percepção e um modo menor de armazenamento na mente? Nosso objetivo é confrontar essa questão que surge nas Primeiras Meditações Metafísicas de Descartes e compreender por que o seu modo de pensar e conceber a imagem é tratada por Sartre como uma metafísica ingênua da imagem. Nesse sentido iremos apresentar as críticas de Sartre a Descartes e as insuficiências que o contemporâneo visualizou no moderno.

Palavras-chave: Consciência. Fenomenologia. Imaginação. Percepção.

Abstract: What is an image, the fruit of a perception and a smaller mode of storage in the mind? Our aim is to confront this question that arises in Descartes' First Metaphysical Meditations and to understand why his way of thinking and conceiving the image is treated by Sartre as a naive metaphysics of the image. In this sense we will present Sartre's criticisms of Descartes and the inadequacies that the contemporary saw in the modern.

Keywords: Consciousness. Phenomenology. Imagination. Perception.

\section{Introdução}

A imagem, segundo Descartes, é uma representação fiel do objeto percebido; ela é a representação da coisa percebida, porém, menor e presente na mente. A imagem habita no limite entre o empírico e o mental. Ora, em Descartes, há uma confusão entre existência e essência. Assim, tanto a imagem como o sonho, fotografia etc. estão dentro de uma mesma concepção existencial; elas constituem uma ideia. Sartre, ao elaborar suas considerações ao problema da imagem, dirige algumas críticas à essa concepção cartesiana. O filósofo contemporâneo apresenta um novo modo de se conceber a imagem. Sartre apresenta-a como um objeto do mundo, com um modo existencial diferente do objeto concreto. A imagem é um modo de consciência. Ela é um ato e não uma coisa; é pura síntese - é criativa - e não é um conjunto de percepções. Sartre mostra a imagem como uma abertura para o mágico, que segundo Sass (2007, p. 44) "é uma queda da consciência, uma alteração do mundo dos objetos”.

Enquanto Descartes ficou preso à uma imagem representativa; uma cópia que induz ao erro por estar associada à percepção, Sartre, por sua vez, apresenta uma imagem que tem uma representação significativa à vida psíquica. Essa maneira de se pensar a imagem forma uma ontologia - à medida em que há modos distintos de se

\footnotetext{
${ }^{1}$ Mestrando no Programa de Pós-Graduação em Filosofia da Universidade Federal de Minas Gerais. Orientando do Professor Simeão Donizeti Sass, estuda a filosofia da psicologia fenomenológica da imaginação em Jean-Paul Sartre. E-mail: helton.filosofia@gmail.com.
} 
pensar a imagem - que Sartre procura explicitar e apresentar. O não esclarecimento dessa ontologia, da reflexão da imagem à vida psíquica, foi a confusão cartesiana de essência e existência, que Sartre termina por identificar como a metafísica ingênua de imagem.

Nesse sentido, o artigo aqui tem em vista, como proposta, apresentar a concepção cartesiana de imagem evidenciando as suas insuficiências identificadas por Sartre e explicitar algumas das considerações deste ao problema.

\section{A concepção da metafísica ingênua de imagem}

$\mathrm{Na}$ modernidade o pensamento de Descartes ganhou muita notoriedade. Talvez isso se dê pelos novos rumos que ele propôs para sua filosofia frente àquele que estava vigente em seu período. Esse destaque que está apoiado na nova ciência que emerge no século XVII e na clareza e método que essa nova cientificidade propõe, legou a Descartes (posteriormente) o nome de filósofo racionalista. No que concerne ao nosso tema e objeto de pesquisa, Descartes também deixou sua consideração. O tema passa pelo problema da imagem a partir da sua teoria do conhecimento e da sua preocupação com uma verdade clara e distinta.

Na sua obra datada entre 1622-1629, Regras para direção do espírito, Descartes nos apresenta as faculdades sensitivas e a faculdade inteligível. Tais faculdades são a estrutura do que Descartes denomina de entendimento. Para o filósofo moderno, a mente é constituída por quatro faculdades, a saber: o entendimento, a imaginação, os sentidos e a memória (DESCARTES, 1999, p. 73). Dessas, apenas o entendimento é capaz de captar a verdade; para isso, é auxiliado pelas demais faculdades. O conhecer, segundo Descartes - nas Regras - advém das propriedades que os objetos fornecem a cada um dos sentidos formando, por assim dizer, uma totalidade desse objeto. Todos os sentidos externos são, contudo, à medida em que são partes do corpo, passivos na sensação, mesmo que o objeto seja aplicado como uma ação. Em outras palavras, Descartes quer nos mostrar que se os olhos captam figuras, elas são impressas graças à ação da luz com uma diversidade de cores e propriedades (DESCARTES, 1999, p. 75). À medida que o conhecer é constituído, ele capta as propriedades que o objeto fornece; partir daí gera-se essa totalidade de propriedades captadas por cada sentido.

Se o sentido externo é colocado em movimento pelo objeto, suas propriedades são transportadas para outra parte do corpo. Essa outra parte é o que Descartes denomina como o sentido comum. Os sentidos comuns são a marca (sinete) que formam na fantasia (ou imaginação) as figuras ou ideias que vem dos sentidos externos puras e incorpóreas. A imaginação é uma parte do corpo que envolve várias figuras distintas e que se retêm por bastante tempo na mente, podendo ser chamada de memória (DESCARTES, 1999, p. 77-78). No entanto, é pela força motriz que o sentido externo passa ao sentido comum. A fantasia, segundo Descartes, é a causa 
de muitos movimentos nos nervos. A fantasia é incorpórea quando há exercício da razão. Por outro lado, quando não há razão, a fantasia é meramente corporal. Descartes não explora ou dá exemplos desse âmbito corporal da fantasia.

Diante, porém, de toda essa exposição, o filósofo francês nos adverte dizendo que "deve-se conceber que essa força pela qual conhecemos propriamente as coisas é puramente espiritual e não mesmo distinta do corpo inteiro" (DESCARTES, 1999, p. 79); ou seja, essa força é única e recebe figuras vindas do sentido comum e ao mesmo tempo que a fantasia - sendo as da memória -, sendo as da imaginação. Em outras palavras, essa força de conhecimento, ora é passiva, ora é ativa. É uma única força que se aplicando com a imaginação, ao senso comum, é chamada de sentidos. A imaginação à medida em que está guarnecida de diversas imagens é chamada de lembrança, ou como vimos, de memória. Ainda, se aplicarmos essa última para dela formar novas imagens, Descartes nos diz que isso é uma imaginação; que agindo sozinhos chama-se compreensão. O que outrora não parecia claro, Descartes clarifica mais adiante no seu texto dizendo que

[...] a mesma força é ainda chamada, quer de entendimento puro, quer de imaginação, quer de memória, quer de sentindo, mas dãolhe propriamente o nome de espírito, quando ora ela forma novas ideias na fantasia, ora baseia-se naquelas que já estão feitas. (DESCARTES, 1999, p. 79-80).

Nessa direção, o entendimento pode ser movido pela imaginação e o contrário também pela força motriz. Os objetos podem atuar sobre a imaginação pintando as imagens desses corpos. O entendimento de algo não pode conter erro. Sendo assim, o espírito não pode ser auxiliado pelas faculdades sensíveis, "pois o entendimento não se ocupa com o corporal ou seus semelhantes" (DESCARTES, 1999, p. 8o). Nessa perspectiva, o entendimento deve despojar-se, ao máximo, a imaginação de qualquer impressão distinta.

\section{A posição de Descartes}

Vimos, até aqui, que a imagem por ora é, segundo Descartes, uma representação fiel do objeto percebido; ela é a coisa percebida, porém menor e na mente. Por outro lado, é uma força capaz de mobilizar os sentidos e formular o saber de algo, isto é, ela forma o conhecer dos objetos. A imagem habita no limite entre o empírico e o mental. Fica claro então que, em termos cartesianos, há uma confusão entre existência e essência. Diversamente dessa concepção clássica, ao apresentar um novo modo de se conceber a imagem, Sartre apresenta-a como um objeto do mundo, com um modo existencial diferente do objeto concreto. A imagem é um modo de consciência. Ela é um ato e não uma coisa, ela é pura síntese - é criativa - e não é um conjunto de percepções. Sartre mostra a imagem como uma abertura para o mágico. 
Enquanto Descartes ficou preso em uma imagem representativa; uma cópia que induz ao erro por estar associada à percepção, Sartre apresenta uma imagem que tem uma representação significativa à vida psíquica. Essa maneira de se pensar a imagem pressupõe uma ontologia - à medida em que há modos distintos de se pensar a imagem - que Sartre procura explicitar e apresentar. O não esclarecimento dessa ontologia, da reflexão da imagem à vida psíquica, é o signo mesmo da confusão cartesiana de essência e existência, que Sartre identificou como a metafísica ingênua da imagem. Sob esse plano, a proposta é apresentar a concepção cartesiana de imagem evidenciando as insuficiências dela identificadas por Sartre e explicitar algumas das considerações deste ao problema.

Em Descartes, o problema da imagem ganha um olhar especial. Dentro da sua epistemologia, a imagem surge como fruto de coisas externas e materiais. Ela é uma ideia que surge a partir de uma afetação externa, isto é, de corpos externos que mantém na mente como coisas menores ou uma representação fiel daquilo que ela, enquanto imagem, remete. A imagem nesse sentido, se limita a uma cópia ou um ser que habita no limite de ser objeto concreto e metal (imagem). Nas suas Regras para a direção do espírito o filósofo moderno nos mostra uma imagem que se constitui como fruto de percepções sensoriais que:

Com efeito, assim como o entendimento pode ser movido pela imaginação ou, pelo contrário, agir sobre ela, assim também a imaginação pode agir sobre os sentidos pela força motriz, aplicando-os aos seus objetos ou, pelo contrário, eles podem agir sobre ela, pintando nela as imagens dos corpos; por outro lado, a memória, pelo menos a corpórea e semelhante à recordação dos animais, não é de forma alguma distinta da imaginação. Conclui-se assim com certeza que, se o entendimento se ocupa do que nada tem de corporal ou de semelhante ao corporal, não pode ser ajudado por essas faculdades; mas, pelo contrário, para que nelas não encontre obstáculo algum, é preciso afastar os sentidos e despojar, tanto quanto possível, a imaginação de toda impressão distinta. Se, por outro lado, o entendimento se propõe examinar um objeto que se pode relacionar com um corpo, é a idéia deste objeto que é preciso formar com a maior distinção possível na imaginação; para mais comodamente o fazer, deve mostrar-se aos sentidos externos o próprio objeto que esta idéia representará. (DESCARTES 1999, p. 8o).

A imagem, em Descartes, num primeiro momento, precisa afastar-se de quaisquer sentidos, mas noutro momento ela precisa ser confrontada com aquilo que ela está remetendo. A imagem é uma associação de elementos percebidos e, fruto de uma ação corporal possibilitada pelos sentidos. Resultando, por assim dizer, em algo material na mente, a imagem, então, é uma representação fiel do objeto concreto. De outro modo, a imagem é uma passividade advinda do movimento do objeto-concreto ou de uma objetividade ativa, que é o entendimento. Limitando-se 
sempre em a uma impressão de algo externo, e alojada no órgão do entendimento como algo puramente intelectual, natural ou comum. É nesse contexto que a imagem é concebida como uma extensão de um objeto concreto. Essa é a insuficiência teórica de Descartes sobre a questão. Descartes não distinguiu a imagem-do-objeto do objeto-concreto, também não diferenciou os dois modos de seres que existem como fenômeno para o entendimento.

Ora, fato é que Descartes, nas Meditações, elabora uma concepção de ideia que é um modo de ser que contém uma causa, necessariamente possuidora de tanta realidade formal quanto de realidade objetiva, e que não pode vir do nada. Visto que,

[...] se supusermos que há na ideia algo que não havia em sua causa, ela o teria obtido, portanto, do nada. E por mais imperfeito que seja esse modo de ser pelo qual a coisa, mediante ideia, é objetivamente ou por representação no intelecto, é seguro, no entanto, que ele não é totalmente um nada e não pode, por conseguinte, provir do nada (DESCARTES, 2013, p. 83).

Se, no entanto, essa ideia conter origem numa outra ideia, essa relação não pode ser ao infinito, pois

[...] deve-se chegar por fim a uma primeira ideia, cuja causa seja um como que arquétipo, no qual esteja contida formal e efetivamente toda a realidade ou perfeição que na ideia está contida apenas objetivamente ou por representação. (DESCARTES, 2013, p. 85)

Esse argumento cartesiano explicita sua metafísica sobre a questão da imagem e complementa a tese de que essas ideias (imagens) são coisas menores na consciência $^{2}$. Ainda nas Meditações, o autor diz que a razão é quem o faz conhecer que as ideias são quadros ou imagens em sua mente e que podem não conservar a perfeição e detalhes de onde está se remetendo, não podendo também ser maior ou mais perfeita do que as coisas de onde foram tiradas.

Se, ainda, essa ideia conter origem numa outra ideia, segundo o autor, essa relação não pode ser ao infinito. Pois "deve-se chegar por fim a uma primeira ideia, cuja causa seja um como que arquétipo, no qual esteja contida formal e efetivamente toda a realidade ou perfeição que na ideia está contida apenas objetivamente ou por representação" (DESCARTES, 2013, p. 83). Esse argumento explicita sua metafísica sobre a questão da imagem e reforça a tese de que essas ideias (imagens) são coisas menores na mente.

\footnotetext{
${ }^{2}$ Sobre essa questão ver: R. Landim Filho; In: Ideia, ser objetivo e realidade objetiva nas "Meditações" de Descartes; Kriterion: Revista de Filosofia, n.55 (130), 2014; p. 669-69o.
} 
Nas Primeiras objeções e respostas, Descartes recebe uma crítica sobre sua concepção de ideia. A crítica feita por Mr. Caterus ${ }^{3}$ explicita o que queremos evidenciar, isto é, que a ideia (imagem) de algo é fruto de uma percepção que copia as estruturas do objeto-concreto. O ser da imagem é um resultado da percepção que se limita em ser imagem perceptiva de algo. A ideia não é uma novidade de uma percepção, mas um modo menor de armazenar na mente a coisa percebida ${ }^{4}$; é uma cópia. Isso não altera a coisa percebida, mas conserva suas estruturas e seu modo. Em outras palavras, aquelas ideias que Descartes denomina fictícias e que são provenientes da imaginação (ideias que originam ideias), são uma combinação de imagens que advém dos sentidos e que se retém na memória, resultando em representações de coisas que aparentemente não vimos, porém elas não desenvolvem nenhuma novidade. A percepção de cavalo torna-se uma representação menor de cavalo na mente e que não tem nenhuma diferença do cavalo real. ${ }^{5}$

Essas ideias são concebidas pela coisa pensante, são representações e projeções perceptivas de vivências passadas. Descartes observa que tais ideias não poderiam vir do nada, mas necessariamente do pensamento. Ou seja, visto que "alguns desses pensamentos são como imagens das coisas e somente a eles convém propriamente o nome de ideia: como quando penso em um homem ou numa quimera ou no céu ou em um anjo ou mesmo Deus" (DESCARTES, 2013, p. 74). Descartes está apenas explicitando a correlação entre imagem, pensamento e ideia; que pensadas como unidade formam um tripé conceitual. Todos esses modos estão ligados à percepção, pois ter pensamento de algo, ter uma ideia de algo e representar algo se constituem a partir de um conjunto perceptivo desse algo; algo esse que será depositado na mente, como se a mente fosse um receptáculo para tais conteúdos (KUJAWISKI, 1969, 122-125). É nesse sentido que os objetos presentes na consciência são necessariamente uma representação fiel dos objetos mundanos. Só assim, a epistemologia cartesiana se concretiza; só pode haver conhecimento à medida em que tais conteúdos estejam correlacionados com os do mundo.

\section{A crítica sartriana a Descartes}

Segundo Sartre, um grande e aparente problema, em Descartes, foi o de não esclarecer os tipos de ideias e suas causas, nem ainda de distinguir, com exatidão, mecanismo e pensamento. Descartes ao limitar o corporal ao mecânico e conceber a imagem como uma coisa corporal, fez da imagem uma "ação dos corpos exteriores sobre nosso próprio corpo por intermédio dos sentidos" (SARTRE, 1936, p. 7). Esse

\footnotetext{
${ }^{3}$ cf.: CEuvres de Descartes, Texte établi par Victor Cousin , Levrault, 1824, tome I; pp. 353-368.

${ }^{4}$ Ver: TEIXEIRA, William de Jesus; Teoria das ideias, inatismo e teoria da percepção em Descartes; Cadernos Espinosanos, n. 35, jul-dez 2016; p. 487-516.

${ }^{5}$ Sobre essa questão, ler as críticas de Mr. Caterus às Primeiras Meditações; especificamente à $3^{\underline{a}}$ Meditação.
} 
empreendimento não poderia resultar senão no erro, pois com essa construção teórica, a imagem não passa de uma coisa inanimada da consciência. Ela limita-se em ser um objeto semelhante aos objetos exteriores. Para Sartre, a imagem não está associada à percepção, ela não é um conteúdo da consciência, haja vista que a própria consciência não tem interior para se opor a um exterior ${ }^{6}$. "Ela é um fluxo para fora de si. A consciência é uma recusa de ser qualquer tipo de substância" (SARTRE; 2005, p. 56). Desse modo, a imagem não está depositada na consciência como uma espécie de objeto, mas é um ato, um fluxo, um tipo de consciência.

Na concepção cartesiana, não é possível distinguir as sensações das lembranças e ficções etc. sendo que, em todos esses casos, há o movimento cerebral. A respeito disso, o que Sartre observa é que "somente o juízo e o entendimento permitem, de acordo com a coerência intelectual das miragens, decidir quais delas correspondem a objetos existentes" (SARTRE, 1936, p. 8). Essa crítica diz respeito à tentativa de Descartes de mostrar os laços corporais que há entre as imagens e os da sua produção. Assim, sendo produzidas pelas percepções que o eu tem do mundo, e por essas percepções induzirem ao erro, a imagem é necessariamente um erro, uma afecção demasiadamente substancializada e unificada à sensação. Pensar não é imaginar, mas ter uma sensação do objeto pensado, visto que a imagem é uma coisa; a coisa pensada idêntica ao objeto do qual o eu percebe à sua frente. Ou melhor, "a imagem não se transformou em nada, não sofreu nenhuma modificação enquanto o céu inteligível se desmantelava, pela simples razão de que, em Descartes, ela já era uma coisa" (SARTRE, 1936, p. 17). A imagem não tem nada de novo; ela é uma cópia e permanece presa à estrutura da coisa da qual se remete.

\footnotetext{
${ }^{6}$ Na sua obra A transcendência do Ego, Sartre tem um extenso trabalho em mostrar que a consciência não pode ser compreendida como uma substância. O intento de Sartre, nessa obra, além de apresentar o caráter sintético e incorporado da consciência é expor sua rejeição a qualquer substancialidade, isto é, a consciência precisa ser limpa e pura de qualquer vestígio substancial. Sartre nota que depois que o campo transcendental é purificado de toda a estrutura egológica, ele recobra sua limpidez. Não há vida interior como opunha Brunschvicg - na sua conferência no congresso internacional de filosofia em Nápoles (maio de 1924) -, pois não há mais nada que seja objeto e que possa pertencer ao mesmo tempo à intimidade da consciência. (SARTRE, 2015, p. 61). Essa tese, aliás, é reforçada por Sartre em Situações I que, segundo o próprio filósofo, "de um só golpe a consciência está purificada, está clara como uma ventania, não há mais nada nela a não ser um movimento para fugir de si, um deslizar para fora de si; se, por impossível, vocês entrassem "dentro" de uma consciência seriam tomados por um turbilhão e repelidos para fora, para perto da árvore, em plena poeira, pois a consciência não tem "interior"; ela não é nada senão o exterior de si mesma; e é essa fuga absoluta, essa recusa de ser substância, que a constitui como uma consciência". (SARTRE, 2005, p. 56). O intérprete de Sartre, Coorebyter, também nos mostra em sua obra, Sartre face à la phénoménologie, que Sartre expulsou o ego da consciência. Essa última é clara como um grande vento. (2000, p. 161). Sartre se ocupou em nos mostrar que não há necessidade de um 'eu' para efetuar as sínteses de operação da consciência. Pelo contrário, a consciência é, ela mesma, esse movimento sintético de se organizar-se à demanda de cada objeto intencionado. O que, em outras palavras, seria o mesmo que dizer que a consciência se organiza em ser consciência ora perceptiva, ora imaginante, ora conceptiva etc.
} 
Outro erro cartesiano, conforme Sartre, foi querer mostrar laços da imagem com o de sua produção. Esse erro se estabelece a partir do momento em que Descartes procurou edificar a imagem como uma coisa. A imagem não pode ser como o objeto. A imagem de uma folha sobre a mesa não é existencialmente igual a folha concreta sobre a mesa; há uma diferença ontológica. O ser da imagem é um ser de pura negatividade que não se realiza, não se concretiza. $O$ objeto percebido é um ser estático, pleno, concreto e que não depende da consciência. Essa é a diferença existencial que há entre o objeto-imagem e o objeto-concreto que Descartes não esclareceu. Há um tipo de aprendizado diferente. A imagem é um aprendizado imediato, sintético e novo; ela não tem o perfilamento e a lentidão do processo de aprendizado perceptivo. A imagem é um modo criativo que nega o mundo tornando-o irreal. A imagem é um desmantelar das estruturas do objetoconcreto. Ela nega o mundo, ela faz da folha sobre a mesa uma negação do objetoconcreto folha sobre a mesa. Ela recusa ser uma coisa; ela é um ato de pura síntese. Por isso, o ser da imagem deve necessariamente ser diferente do objeto do mundo. É que a imagem não é apenas uma transformação; é uma negação de ser substância, de ser cópia e de ser percepção.

Segundo Sartre, a imagem não pode ser apenas uma junção de elementos percebidos, pois isso não é criar, mas unir elementos sensoriais. Se a imagem for esse limite de existência, estaria sob a substancialização e materialização de sua existência. Ora, isso corresponde a tudo o que a imagem não pode ser. $\mathrm{O}$ ser da imagem de Monalisa não é ser uma união da percepção da esposa de Francesco del Giocondo, de Isabel de Aragão ou um autorretrato de Leonardo da Vinci, mas uma criação, uma síntese e negação do mundo perceptivo para tornar possível e criativo sob um ângulo particular a imagem Monalisa. Isto é, a imagem é o modo com o qual se visa um objeto. A imagem é a abertura para o mágico, uma queda da consciência, uma alteração do mundo dos objetos (SASS, 2007, p. 44). Todo esse aparato explicita a diferença da imagem com a percepção. Quer dizer, para Sartre, a percepção é uma vivência intencional como a imaginação; no entanto, ambas se diferem em suas intenções. Segundo ele, Husserl não faz uma indicação do porquê da questão ${ }^{7}$, e, sob esse aspecto, Husserl precisa abandoná-lo, como fez com Descartes e outros teóricos e seguir adiante por si mesmo. Sartre diz que a imagem externa, como uma fotografia, quadros, pinturas etc. tem uma mesma matéria impressional que a percepção.

A imagem mental não tem nada de perceptual. Pois o duende fumante que imagino neste instante não tem nada de real, nem contém uma matéria impressional da qual percebi a pouco. Ele é um nada e não habita em lugar nenhum

\footnotetext{
${ }^{7}$ Embora Sartre diz que não, Husserl não trata a questão à maneira de Sartre, pois como nos fala M. E. Saraiva (2012), Husserl em Meditações Cartesianas aborda o tema da imaginação e percepção como síntese de presentificação passiva. Isto é, elas estão sob domínio da experiência ante judicativa e consequentemente uma associação temporal.
} 
fora de nós. A questão que Sartre se coloca é a de compreender onde está a diferença entre imagens e percepções e, sobretudo, compreender, mesmo depois da redução fenomenológica, como reencontrar um mundo real e um imaginário. A percepção, por outro lado, aqui em L’imagination, toma um caráter degradante à medida em que ela não consegue extrapolar o campo do existente. Há uma nítida diferença entre percepção e imaginação e Sartre nos mostra qual é dizendo que,

A árvore pura e simples, a árvore na natureza não é nada menos que essa árvore-que-percebo-como-tal, que pertence como o-que-épercebido ao sentido da percepção de uma forma alienável. A árvore pura e simples pode queimar, se dissolver em seus elementos químicos etc. mas o sentido - o sentido desta percepção aqui, um elemento que parece necessariamente ao seu sentido - não pode queimar, ele não tem elementos químicos, não tem forças, ele não tem propriedades reais. Então, onde está a diferença? Como que se explica que haja imagens e percepções? [...] Tudo vem, responderse-á, pela intencionalidade, isto é, pelo ato noético. (SARTRE, 1936, p. 154-155).

A questão está no campo sintético. Noutras palavras, a imagem é uma síntese ativa; ela é uma modificação e, se preferirmos, ela é uma espontaneidade. Já a percepção, é colocada por Sartre como uma síntese passiva, pois todo o domínio da experiência antepredicativa, tudo o que é tido como associação temporal e que passa diante da atividade categorial é síntese passiva. Compreendemos que a percepção sensível, como nos mostra Saraiva (2012, p. 164), são presentificações e que pressupõe uma camada inferior que recebem os objetos de maneira passiva. E isso torna a percepção um modo de organização da consciência degradante e distinto da imagem. De outro modo, "a diferença entre imagem-ficção e percepção procederia, pois da estrutura profunda das sínteses intencionais”. (SARTRE, 1936, p. 158). Esse ponto, Sartre desenvolve melhor em sua obra de 1939, L’imaginaire onde tal diferença com a imaginação torna mais explicita.

Sartre ainda argumenta que a percepção é um modo da consciência e a cadeira que percebo a minha frente é um objeto para essa consciência. Para ele, a consciência tem três maneiras de ser consciência dos objetos e uma dessas maneiras é a percepção, como também a imaginação e a concepção. No que concerne à percepção, o seu objeto transcendente se dá por perfis e, sob esse prisma, Sartre nota que, "na percepção, eu observo os objetos". (SARTRE, 2016, p. 23). É próprio da percepção que seu objeto apareça sob uma série de perfis e o objeto ele mesmo é uma síntese de toda essa série de aparições. (SARTRE, 2016, p. 23). Não podemos, contudo, confundir conhecer com perceber. Sartre nos adverte acerca disso, pois não se percebe um pensamento e não se pensa uma percepção. Pois pensar é conhecer a consciência que é posta no centro do objeto enquanto perceber é uma unidade sintética de uma multiplicidade de aparência que faz o "saber se constituir de maneira lenta”. (SARTRE, 2016, p. 25). 
A percepção é o modo de a consciência se organizar e colocar o seu objeto como um existente. $\mathrm{E}$ isso faz dela uma passividade à medida em que os elementos propriamente representativos corresponde à passividade da consciência. É que os seus objetos são constituídos por uma multiplicidade infinita de determinações e de relações possíveis. Em função disso, talvez, a tese husserliana de que a percepção parece-nos algo como sendo se mostra plausível: [1] percepção própria e percepção externa; [2] percepção sensível e percepção interna. O que isso quer dizer? Em [1], Husserl nos mostra uma percepção do eu e de coisas externas. A percepção tem sim a sua importância na apreensão dos objetos, entretanto, não há uma evidência apodídica. Isso quer dizer que mesmo o objeto estando frente à consciência que o intenciona, ele não pode ser completamente esgotado em si, pois possui uma abertura de indeterminadas possibilidades. (HUSSERL 2001, §9; p. 40). Em [2], Husserl nos mostra, por um lado uma percepção que se apoia nos órgãos sensoriais e no movimento da consciência ao voltar à vivência - pensar, querer etc. (CURVELO, 2014; p.2). Por outro lado, a percepção é o que acompanha as vivências atualmente presentes, o que significa que essa percepção é a que corresponde com as fases do ato intencional da temporalidade. Ou seja, é uma percepção que trabalha com o objeto presente em ipseidade e esse objeto é capitado naquilo que ele mesmo é.

Sartre está de acordo com tais considerações de Husserl. Para ele, o objeto apresenta como múltiplas possibilidades. Assim, a cada lida com ele há um aprendizado que depois de uma síntese chega-se ao saber-do-objeto. Isso tudo ocorre com objeto aí, como essa cadeira, aí, bem à minha frente. O modo de a consciência conhecer objeto, para Sartre é, como nos mostra Souza, "é a observação, na qual ele é dado de um lado de cada vez, por perfis e ângulos - o que faz com que não seja possível apreendê-lo de uma única vez". (SOUZA, 20o8, p. 86). É nesse sentido que o movimento perceptual se constitui e as múltiplas possibilidades aparece à percepção, mas mesmo assim o objeto está ali e sempre afirmado com um existente. Ele está preso às determinações do tempo e do espaço. Isso nos mostra a preocupação de Sartre em querer se distanciar do idealismo husserliano e compreender que "o mundo real escapa ao conteúdo noemático que possamos lhe atribuir e que tem existência autônoma, ainda que só nos pareça através das intenções de nossa subjetividade". (PERDIGÃO, 1995, 67). O que implica ainda que, para Sartre, o mundo já está dado e que tais objetos que o compõe estão determinados sob o tempo e o espaço. $\mathrm{O}$ agir da consciência (intencional) capta os objetos nessa determinação, pois o objeto é contemplado no espaço exterior. É desse objeto, preso, determinado e dado à consciência que ela retira o saber-desse-objeto. Quer dizer, mesmo que essa cadeira esteja ali, dada imóvel e que não dependa de nenhuma consciência para existir, 
[...] na percepção, a consciência retira o seu saber do objeto, o que é sempre capaz de revelar o que ignoramos, ou ainda de nos enganar e nos surpreender, porque não fomos nós que o criamos. Por isso, nosso saber vai se formando lentamente: só podemos perceber o objeto de um certo ângulo, e precisamos multiplicar os nossos pontos-de-vista para tirar uma síntese. (PERDIGÃO, 1995, p. 66).

Só percebemos o encosto, o assento e algumas de suas pernas. Isso não nos apresenta a totalidade da cadeira. A cada lida com ela apreendo mais e desse aprendizado estabeleço sínteses desse nível de conhecimento. Aqui temos uma notória distinção da percepção e imaginação, já que ambas visam o objeto de maneiras diferentes. Na imaginação, a consciência se organiza em visar um nada (rien) e, na percepção, a consciência visa um ser concreto, um ser ali, presente e estático como essa cadeira à minha frente. O perceber é uma unidade sintética de múltiplas aparências, como nos mostra Souza (2008, p.86) e, dessa organização é que emerge o aprendizado. Como, enfim, tentamos mostrar anteriormente, da imagem não advém nenhum aprendizado, uma vez que ela se dá de uma única só vez.

Conforme avalia Sartre, Descartes não contemplou os diferentes tipos de imagem. Ora, essa não se limita em ser apenas uma pintura; ela é lembrança, fotografia, sonho etc. A imagem representa um papel significativo à vida psíquica. A consciência (de) imagem (consciência imaginante) se estabelece como um ato que reage ao objeto como um nada, e está ligada ao que Sartre chama de "analogon", isto é, o signo do provável que se estabelece por um saber do objeto, pela intencionalidade objetiva de um ângulo particular. O analogon é o movimento de formação da imagem e a designação do objeto-imagem ${ }^{8}$. Para Gontijo (2005, p. 56),

Sartre ao conceber a noção do analogon da imagem mental diz que a intenção de uma imagem é carregada de conhecimento, porque representamos sempre uma imagem que já conhecemos e que desejo representar como tal. Portanto, uma imagem para existir depende de um saber que a constitua".

\footnotetext{
${ }^{8}$ Como nos mostra Bianca Spohr, "O analogon seria, então, segundo Sartre, este elemento que "preenche" a intenção da consciência imaginante, de modo que se a idéia é visar o rosto de um ente querido, não adianta dirigir-se para qualquer objeto. São necessários 'determinados' objetos, aqueles que têm alguma relação com a pessoa que se quer retomar (em imagem)". (SPOHR, 2009, p. 70). Spohr está dizendo em outras palavras o que Sartre nos apresenta na sua obra $O$ Imaginário. O analogon é o que tem a capacidade de animar a intenção daquilo que quero ter como imagem a partir de alguma matéria que fomente o surgimento da imagem. (SARTRE, 2016, p. 42). Isso é o que nos esclarece Dufourcq dizendo que "O analogon é, segundo a definição dada, uma realidade presente, 'uma certa matéria', que poderia ser percebida, mas que desempenha na imaginação o papel de apoio com o objetivo de dar ao objeto imaginário uma aparência de presença. $\mathrm{O}$ analogon é tomado como um representativo, diferente do objeto, possivelmente se assemelhando a ele, e através do qual ele é direcionado. Por exemplo: as cores e formas na tela, os gestos do imitador, as sonoridades e a fisionomia das palavras, mas também uma nuvem ou nossos estados emocionais ou atitudes e movimentos do nosso corpo." (DUFOURCQ, 2010, p. 11-12).
} 
A intérprete está nos alertando para uma característica fundamental da imagem: essa não tem um saber, não tem um conhecimento para ser apreendido. A imagem se dá de uma única só vez, pois é pobre essencialmente e depende de um conhecer prévio para ser constituída como imagem. A imagem é a representificação da vida psíquica pela compreensão simbólica do conhecer ${ }^{9}$. Essa é a abertura para a vida imaginária, por criar um novo mundo; o irreal.

\section{Conclusão}

À guisa de conclusão, o tentame foi apresentar as críticas sartrianas à Descartes acerca do problema da imagem, além de elucidar algumas insuficiências que Sartre localizou no pensador do século XVII. Na edificação de um constructo teórico, Descartes mostrou que a imagem é algo material e fruto de uma percepção. Ela é uma representação de algo que induz ao erro como ele apresenta em Regras para direção do espírito; regra XII. Já nas Meditações, Descartes busca uma ideia primeira, isto é, uma causa que seja objetiva ou representada nas demais ideias. De outro modo, ele busca uma causa que justifique a realidade e a formalidade da ideia; uma objetividade e formalidade do qual a imagem seja. Ele, porém, afirma mais

\footnotetext{
${ }^{9} \mathrm{O}$ psíquico é uma unificação de consciências do qual chamamos de eu, personalidade ou ego, mas "a concepção do Ego que propomos nos parece realizar a liberação do campo transcendental ao mesmo tempo que sua purificação. O campo transcendental, purificado de toda estrutura egológica, recobra sua limpidez primeira. Em um sentido é um nada, uma vez que todos os objetos físicos, psicofísicos e psíquicos, todas as verdades, todos os valores estão fora dele, já que o meu moi cessou, ele mesmo, de fazer parte dele. Mas esse nada é tudo, pois é consciência de todos esses objetos." (SARTRE, 2015, p. 61 - grifos do autor). Sartre começa por mostrar que o ego não está na consciência como outros autores acreditavam. Ele mostra que o ego está fora da consciência para não interromper o seu fluxo. Em outras palavras, "na visão de Sartre, a presença de um ego dentro da consciência de fato interromperia a unidade de seu fluxo temporal. O ego impediria que o sujeito vivenciasse sua vida, seja em auto-afeição direta ou na memória, à maneira do cogito, ou seja, 'sem intermediários'." (STAWARSKA, 2002, p. 95 - grifos da autora). O psíquico, nesse sentido, é a unificação resultante de uma série de consciências que se organizam em ser consciência de algo, o ego se instaura no momento em que a consciência projeta sua espontaneidade no objeto, no entanto essa espontaneidade que é posta sobre o objeto e que desvela o meu olhar subjetivo sob algo. Nas palavras de H. E. Barnes o psíquico é o resultado da consciência 'trabalhando' seu próprio passado (BARNES, 2006, p. 29). Acreditamos que é nessa perspectiva que Sporh diz que o psíquico é fruto de n's consciências imaginantes, perceptivas, conceptivas, emotivas, reflexivas etc. (SPORH, 2011, p. 920). O psíquico é toda a síntese relacional que já fora intencionada e vivenciada pela consciência se sintetizando como uma particularidade, 'um para mim' para o sujeito que se emociona, que percebe e que imagina. A imagem pode ser compreendida como um esquema que visa simbolizar. A função simbólica da imagem, nesse sentido, só poderia ser de presentificar, haja visto que o esquema simbólico não é a própria compreensão. O objetivo da imagem como esquema simbólico do nosso pensamento, neste caso, é presentificar algo para que a compreensão se realize. Esse movimento é o que faz da imagem um correlato da compreensão. A imagem, contudo, não é um pensamento, pois nela não há um saber e aqui neste caso ele deve ser pensada como algo simbólico que é constituído por um certo modo de julgar e sentir. A imagem, entendida como um esquema que visa simbolizar, ou seja, exprimir um conjunto de relações conceituais que são captadas a partir das relações entre os dados sensoriais. Para que, enfim, o pensamento nos seja acessível de maneira decifrável é necessária uma atitude imaginante antes de sua expressão em sua formação. (SARTRE, 2016, p. 187-235). O sujeito imaginante é aquele que nega o mundo e o irrealiza com o objetivo de dar a ele uma nova perspectiva. Negar a folha sobre a mesa é tê-la em imagem para mim, é concebê-la em chamas.
} 
adiante que a imagem não pode ser tão perfeita quanto o objeto concreto, nem conservar tantos detalhes como o objeto concreto. Elas são cópias menores, representações inferiores da coisa concreta. E como Caterus mostra nas primeiras objeções, ela é uma representação vazia, pois não há nada de novo nessa imagem.

Pensar a imagem, por essa via, é limitá-la. É fazer dela algo corporal e confundi-la como um registro da percepção, ou seja, uma descrição de algo percebido. A imagem pensada nessas estruturas não está viva, mas inanimada de consciência. Sartre apresenta outra via para se pensar a imagem. A via da fenomenologia, da negação, criatividade e de ser animada, isto é, um modo de consciência.

Confrontadas as críticas, é possível notar a ingenuidade que Sartre diz haver em Descartes por manter a imagem no mesmo campo existencial dos objetos, como também, limitar todos os tipos da imagem como sendo iguais, quer dizer, como algo material e inanimado de consciência.

Como buscou mostrar, a imagem que Sartre concebe é um análogon, o ângulo particular que se estabelece pelo saber do objeto via intencionalidade. Ou seja, ela é o signo do provável, a abertura para a irrealidade. A imagem é um ser em movimento contínuo, seu processo é de se formar imagem e de se desmantelar enquanto imagem. Ela não se estrutura da mesma maneira do objeto-concreto, seu ser é necessariamente distinto do ser-em-si ${ }^{10}$. Ser imagem é ser um modo de consciência, uma negação. Negar o objeto do qual ela remete é tornar-se pura síntese o que acaba por desmantelar a concretude do objeto-concreto. Ser imagem é criar, movimentar-se e recusar ser qualquer tipo de substância. É recusar ser qualquer junção perceptiva; pois como vimos, percepção é uma organização de a consciência ser perceptiva. Um aprendizado lento que se estabelece por perfilamento, a consciência imaginante (modo de a imagem ser consciência), por outro lado, é um aprendizado imediato. Pura síntese e criatividade. A imagem é em si mesma algo novo.

\section{Referências}

ALVES, I. S. "Consciência imaginante e analogon: o lugar do objeto estético na obra de Sartre”; in Sapere Aude - Belo Horizonte, v. 6 - n. 12, p. 484-497, jul/dez. 2015.

BARNES, H. E. Sartre's Ontology: the revealing and making of being. Sartre Cambridge Companions, Cambridge University Press, 2006.

CASTRO, T. G e GOMES, W. B. "Da intencionalidade da consciência ao método progressivo regressivo em Husserl”. In: Psicologia USP, v.26, n.1, p. 90-99, São Paulo, 2015.

CASTRO, F. C. L. de. A ética de Sartre. São Paulo: Loyola, 2016.

CESCON, E. A doutrina husserliana da consciência. Um estudo a partir das Investigações Lógicas ( $\left.V^{\underline{a}}\right)$ e das Meditações Cartesianas ( $\left.V^{\underline{a}}\right)$. Dialegesthai, p. 1-21.

\footnotetext{
${ }^{10}$ Modo de ser estático, que esgota em si e que não depende de nenhuma consciência para existir.
} 
CURVELO, F. V. "As críticas de Husserl à teoria das percepções interna e externa em Brentano”. In: Scientiarum Historia VII; Rio de Janeiro,2014.

DA SILVA, L. C; VACCARO, M. M. “A constituição do sujeito: uma reflexão a partir de JeanPaul Sartre”. In: Revista de Psicologia, v. 7, n. 2, p. 99-109, 2016.

DESCARTES, R. Euvres de Descartes, Texte établi par Victor Cousin, Levrault, 1824, tome I (pp. 353-368).

. Meditações sobre filosofia primeiras. Trad. Fausto Castilho. Campinas, SP: Editora Unicamp, 2013.

. Regras para direção do espírito. Trad. João Gama. Lisboa: Edições 7o, 1989.

DUFOURCQ, A. La dimension imaginaire du réel dans la philosophie de Husserl. Dordrecht, Heidelberg, London: Springer (Phaenomenologica), 2010.

FLAJOLIET, A. La première philosophie de Sartre. Paris Honoré Champion, 2008.

FUJIWARA, G. "Região fenomenológica \& esfera psíquica em Sartre: esboço para uma genealogia do mágico”. In: Griot: Revista de Filosofia, v. 11, n. 1, p. 45-66, 2015.

GONTIJO, R. A Fenomenologia da imaginação em Jean-Paul Sartre: caminho para uma interpretação estética da liberdade. Belo Horizonte, UFMG/Fafich, 2005. [Dissertação de mestrado].

HUSSERL, E. Meditações cartesianas, introdução à fenomenologia. Tradução de Frank de Oliveira. São Paulo: Madras, 2001.

LANDIM FILHO, R. "Ideia, ser objetivo e realidade objetiva nas" Meditações" de Descartes”. In: Kriterion: Revista de Filosofia, v. 55, n. 130, p. 669-69o, 2014.

LIMA, P. O. A noção fenomenológica de ego transcendente em Jean-Paul Sartre. Goiânia, UFG, 2013 [Dissertação de mestrado].

MELLO, D. P. de. "A reflexão sobre a imagem e sua relação com a obra de arte no pensamento de Jean-Paul Sartre”. In: Theoria; v. 7, n. 18, p. 18-26, 2015.

PERDIGÃO, P. Existência e liberdade: uma introdução à filosofia de Sartre. Porto Alegre: L \& PM, 1995.

SARTRE, J-P. L'imagination. Paris: PUF, 1936.

. L'imaginaire: psychologie phénoménologique de l’imagination. Paris: Gallimard, 1948. 1966. . La transcendance de l'ego: esquisse d'une description phénoménologique. Paris: Vrin,

. Situações I. Trad.: Cristina Prado. São Paulo: Cosac Naify, 2005.

Esboço de uma teoria das emoções. Trad. Paulo Neves. Porto Alegre: L\&PM, 2008.

SASS, S. D. Esboço de uma teoria sartreana das emoções. In: Reflexão, Campinas, 32 (92). p. 35-49, jul./dez., 2007.

SILVA, G. D. da. O problema da objetividade da representação nas Primeiras Objeções das Meditações Metafísicas de Descartes; Filogenese, Vol. 7, n. 1, 2014.

SPOHR, B. "A noção de psíquico na teoria do imaginário de Sartre”. In: Psicologia USP, v. 22, n. 4, p. 907-925, 2011.

STAWARSKA, B. Memory and subjectivity: Sartre in dialogue with Husserl. Sartre Studies International, v. 8, n. 2, p. 94-111, 2002. 
ROMUALDO, $\mathrm{H}$.

Submissão: 27.07.2018 / Aceite: 15.09.2018.

101 